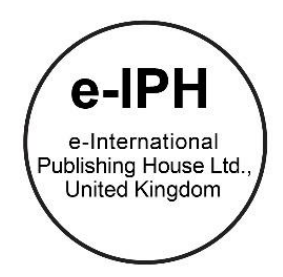

\title{
Interactive Learning in Statistics and Students Performance in Higher Education
}

\author{
Siti Fahazarina Hazudin ${ }^{1}$, Nor Habibah Tarmuji *2, \\ Nurul Nadia Abd Aziz ${ }^{3}$, Indarawati Tarmuji ${ }^{4}$, Nor Aini Hassanuddin 5
}

${ }^{1}$ Faculty of Business and Management, Universiti Teknologi MARA, Jengka, Pahang, Malaysia . ${ }^{2}$ Faculty of Computer and Mathematical Sciences, Universiti Teknologi MARA Pahang, Jengka, Pahang, Malaysia. ${ }^{3}$ Faculty of Business and Management, Universiti Teknologi MARA, Raub, Pahang, Malaysia. ${ }^{4}$ Faculty of Accountancy, Universiti Teknologi MARA Selangor, Puncak Alam, Selangor, Malaysia. ${ }^{5}$ Faculty of Computer and Mathematical Sciences, Universiti Teknologi MARA, Kuala Terengganu, Terengganu, Malaysia

fahazarina@uitm.edu.my,norhabibah@uitm.edu.my,nurul_nadia@.uitm.edu.my, indarawati@uitm.edu.my,norai548@uitm.edu.my 0139947174

\begin{abstract}
This study aims to examine the effectiveness of applying integrated learning tools to study statistics in a particular topic of sampling techniques. The researchers developed an interactive application, referred to as e-SampTec II, to enhance the overall student learning process. Based on a sample of 92 students from the Diploma of Applied Sciences at Universiti Teknologi MARA, Pahang, the mean test scores of the experimental group and control group were found to be significantly different at the $5 \%$ level. These results suggest that employing technology-assisted pedagogy can be a more compelling medium for teaching and learning the current university generation, and in turn, to enhance their overall study performance.
\end{abstract}

Keywords: Higher education; Interactive learning; Statistics; e-learning

eISSN: 2398-4287 @ 2020. The Authors. Published for AMER ABRA cE-Bs by e-International Publishing House, Ltd., UK. This is an open access article under the CC BYNC-ND license (http://creativecommons. org/licenses/by-nc-nd/4.0). Peer-review under responsibility of AMER (Association of Malaysian Environment-Behaviour Researchers), ABRA (Association of Behavioural Researchers on Asians) and cE-Bs (Centre for Environment-Behaviour Studies), Faculty of Architecture, Planning \& Surveying, Universiti Teknologi MARA, Malaysia. DOI: https://doi.org/10.21834/ebpj.v5iSI1.2313

\subsection{Introduction}

Current trends reveal that e-learning has become a prominent teaching tool and acts as an alternative to traditional classroom learning (Zhang, Zhou, Briggs, \& Nunamaker, 2006). The development of e-learning primarily aims to deliver the content of training or education quickly, effectively, and economically (Halachev, 2009a). Zhang et al. (2006) demonstrate that e-learning plays an essential role in a student's academic performance. E-learning is also expected to resonate with today's millennial students, who typically love to explore online, and are proficient in using computers and the Internet.

In a more specific context, it can be debated that teaching statistics courses using traditional methods does not necessarily improve the understanding of students at higher education levels (Zhang, Zhao, Zhou, \& Nunamaker, 2004). As Weltman and Whiteside (2010) claim, active learning outcomes would demand students to be more active and participative with some degree of flexibility in controlling their learning process. Course contents should be carefully designed and incorporated with the use of advanced technology to achieve some teaching and learning objectives, particularly for the topic of topics (Chance, Ben-Zvi, Garfield, \& Medina, 2007).

In this regard, we have initially attempted to capitalize on the e-learning approach by teaching students the most challenging topic in statistics, i.e., sampling techniques. Based on the experience of lecturers teaching the "Introduction to Statistics" course, it was found that the students consistently scored the lowest marks for the topic of sampling techniques. Therefore, we designed the content of this particular topic to be embedded with a computerized interactive software using Microsoft PowerPoint and Excel. These two software

eISSN: 2398-4287 ( 2020. The Authors. Published for AMER ABRA cE-Bs by e-International Publishing House, Ltd., UK. This is an open access article under the CC BYNC-ND license (http://creativecommons.org/licenses/by-nc-nd/4.0/). Peer-review under responsibility of AMER (Association of Malaysian Environment-Behaviour Researchers), ABRA (Association of Behavioural Researchers on Asians) and cE-Bs (Centre for Environment-Behaviour Studies), Faculty of Architecture, Planning \& Surveying, Universiti Teknologi MARA, Malaysia.

DOI: https://doi.org/10.21834/ebpj.v5iSI1.2313 
applications were used for practical guidance in mastering the core concept of sampling techniques because students were familiar with them due to their ease of access and use. Besides, the content of the sampling techniques topic was also developed using i-Spring Suite 8.0 to enhance its overall attractiveness; hence, it facilitates better online readability. The software also incorporates an online quiz and test assessments. Additionally, a flow chart was created as a graphical guideline to select the most suitable sampling technique for the research design. An interactive learning package in this interactive learning project was created, which is coined as e-Sampling Techniques II (e-SampTec II).

The primary objective of this study is to examine the difference in the learning performance of students in two independent groups (i.e., experimental and control). The students were assigned 10 case studies to identify the best sampling techniques and present their answers to the class. At the end of the lesson, a standard test was given to both groups on sampling techniques. The subject test scores were recorded and analysed using descriptive statistics and an independent t-test to examine the difference between the learning performance of the two groups.

\subsection{Literature Review}

Pena-Sanchez (2009) defined e-learning as "a delivery process of knowledge through different electronic media technologies, including the internet, intranet, extranet, satellite broadcast, audio/videotape, interactive TV, CD ROM, etc." (pg. 392). According to Chang (2016), interactive learning is a learning approach that focuses on integrated e-learning and face-to-face learning. The core aim of interactive learning is to ensure that the process of learning can stimulate learners' interests, report their progress, and have tutors provide their feedback and guide learners to the expected targets"(pg.476). Using an interactive computerized medium within an e-learning environment could be an active learning and teaching method in higher learning education. In order to determine the overall effectiveness of interactive learning, prior studies have provided guidelines as a reference on its design and implementation (Chance et al., 2007; Liaw, 2008; Sawang et al., 2013; Zhang et al., 2006).

The interactivity of any educational system software, along with its design and usability, should focus on the effectiveness of the elearning process and control by the instructor or developer (Macgregor \& Turner, 2009). Consequently, JavierSese (2013) found that the role of clickers is significant and should be addressed to promote a high level of interactivity among peers and educators. He also found that there is a positive influence on active collaborative learning and engagement to enhance student learning performance. Besides that, the reliability of the system is strongly related to course performance (Johnson, Gueutal, \& Falbe, 2009).

Another attribute of a superior design of interactive learning tools or devices found in literature is the utilization of interactive visualization. One condition noted by Patwardh and Murthy (2015) is that the degree of interaction varies in accordance with different types of knowledge. It was suggested that interactive visualization should be embedded with what they referred to as 'Interactivity Enriching Features,' allowing some variables to be modified. The use of graphics in delivering content can be beneficial for students to grasp the root of knowledge, particularly in learning statistics, which is highly numerical is mainly composed of technical concepts (Chance et al., 2007).

The intended performance of having a superior design in the interactive tool cannot be guaranteed if the technology and the learner factors are ignored. The other factors that should be taken into account are the age of the learners and their meta-cognitive activity (Johnson et al., 2009). Furthermore, the delivery of teaching and learning instructions, combined with creativity and technology-driven tools, can enable the e-learning process to produce improved learning outcomes (Gunasekaran et al., 2002). Moreover, students' active involvement should be encouraged (and not ignored) when designing an effective learning system, since active participation in the learning process significantly affects learning gains (Wang et al., 2015).

Some studies presented the positive effects of employing an interactive learning design for learning outcomes. For example, Halachev (2009b) found that the use of interactive learning could improve the overall quality of education, and consequently reduce dropout rates. Additionally, Aliasgari et al. (2010) point out that using computer-assisted instruction can improve student learning levels. Furthermore, Qudrat-Ullah (2010) found that incorporating interactive learning through system dynamics simulations could produce the intended learning benefits, especially when dealing with decision making and learning in complex and dynamic tasks.

Previous studies also demonstrate that students manage to learn better with a combination of both words and images (which technology enables) compared to using words alone, and some students prefer to use simulation-based learning (Novak et al., 2014). Students also can potentially become more independent, proficient researchers with the help of technology usage (Al-Hariri and AlHattami, 2017). Besides that, recent studies claim that educational processes must be in line with current advances in technology (Ivanović et al., 2018). Therefore, it is essential to use different technology-enhanced learning tools and machines such as e-SampTec II, in order to enhance students' overall understanding of sampling techniques.

However, the inclusion of electronic and technology education to replace the capacity of traditional teaching methods does not necessarily imply persistence in the intended performance. In their research on the excellent way between conventional and e-learning methods in studying Mathematics and Statistics courses for engineering students in one of the leading universities in Malaysia, Tawil et al. (2017) conclude that a traditional teaching method is still an attractive option for the most suitable manner to learn the mentioned courses. Weltman and Whiteside (2010) made an important observation regarding the scenario of using active learning via the use of interactive teaching materials. They conclude that higher-performing students receive better cumulative grade points (CGPA) through traditional methods of teaching. In other words, the students with lower CGPAs achieved better results when exposed to the active learning approach through interactive-supported teaching materials. This claim is consistent with an earlier study done by Jamie (2002), 
who found that computer simulation methods tend to be more effective for lower-ability students. This serves as evidence that the effectiveness of the interactive learning method is conditional upon the academic level of the students.

Scholars have offered critical recommendations for teachers to implement interactive learning using software, specifically for statistical subjects, and to structure the guidance carefully so that students can focus on the problems and mathematical contents (Chance et al., 2007). Otherwise, students will only pay attention to the software (tool), and blindly follow the list of commands without understanding the critical statistical concepts. Some researchers (Chance et al., 2007; Zhang et al., 2006) even debate that the application of interactive learning does not necessarily have positive effects on learning performance, since it may only lead to a better teaching delivery system. However, student achievements still depend on the manner in which the delivery system is used. Some researchers (e.g., Macgregor \& Turner, 2009) found that the use of interactive learning methods is at least as effective as a traditional teaching method, thus giving an inconclusive direction over the effectiveness of interactive learning.

Since the conclusion on the effectiveness of interactive learning on student performance varies, this study attempts to verify whether using the interactive learning method could possibly assist students at higher learning institutions to have a better learning process to learn statistics, for the topic of sampling techniques in particular. It is crucial to obtain feedback about these interactive software tools so that further improvement in the design can be initiated. In order to assess the effectiveness of this interactive learning approach, this study aims to investigate its effect on students' learning performance by using an experimental study. More specifically, this study examined whether there exists any significant difference in performance between the students who were taught using the traditional teaching method, and those who utilized the interactive learning method.

The next section presents the methods used to achieve the objective of the study. The section following this describes and discusses the results of this study. The final chapter offers the conclusion and recommendations of the study.

\subsection{Methodology}

This preliminary study involved 92 students, which fall into four independent groups taking the Diploma in Applied Sciences program at UiTM Pahang, Jengka Campus. The students were divided into two main groups, namely, the experimental group and the control group, with 50 and 42 students in the respective groups. All the respondents were homogenous based on their average previous mathematics achievements. The experimental study was utilized by the researchers to achieve the objective of the research. The aim of this research is to test the effectiveness of the new teaching method on the topic of sampling techniques. Sampling techniques are the first topic that the students learn in the first two weeks of the semester. The standard syllabus was designed for science and non-science background students in the Introduction to Statistics course. The sampling techniques are taught to the students to allow them to identify various sampling designs and data collection methods, enabling them to apply the appropriate statistical purposes in real-world case studies. The control group was learning using the traditional teaching method, while the experimental group was learning using the interactive learning tool known as the "e-SampTec II."

The "e-SampTec II" was designed by the embedded application of interactive notes using i-Spring Suite 8.0, Microsoft PowerPoint, and Excel. The main advantages of e-SampTec II are its accessible and straightforward application software, the minimal developmental cost, as well as the possibility of offering a promising teaching tool that is easy to use and user-friendly for both educators and learners. Therefore, it was expected that "e-SampTec II" can be used as a platform for interactive assessments for the experimental students in order to enhance their understanding, particularly on the selection of the right sampling technique for a given research context. The duration for the interactive learning exposure and the traditional teaching method was set as eight contact teaching hours, based on the syllabus requirements. This statistical application provided interactive notes linked to e-SampTec II, which shows a systematic process to identify the correct sampling technique for a better learning experience and a useful research guide tool. Besides this, the class instructor, who is an experienced statistics lecturer, guided them on utilizing the courseware.

\subsection{Findings}

Table 1 displays the marks obtained for questions tested about sampling techniques (full score $=14$ marks). According to the table, the average target achieved by the students in the control group is 7.89 , which is lower than the average score of the experimental group (10.95).

Table 1. Independent Sample T-Test Statistics

\begin{tabular}{lc}
\hline Item & Statistics \\
\hline Mean (standard deviation) for Control Group & $7.89(2.89)$ \\
Mean (standard deviation) for Experimental Group & $10.95(2.79)$ \\
Mean difference & 3.06 \\
t-value & 5.17 \\
df & 90 \\
Sig. (2 tailed) & $.000^{*}$ \\
$95 \%$ Confidence Interval of the Difference & $(1.88,4.23)$ \\
\hline \multicolumn{2}{c}{$p<0.05$}
\end{tabular}

Further analysis was conducted using an independent Sample T-Test to compare the marks obtained by the control and experimental groups, as well as to investigate a statistically significant mean difference between the two groups. Based on Table 1, there is a significant mean difference (3.06) in the marks for the experimental group $(M=10.95, S D=2.79)$ and the control group $(M=7.89, S D=2.89)$; 
where the t-value is 5.17 and $p$-value is 0.000 ( $p$-value < 0.05 ). The result is also supported by the $95 \%$ confidence interval of the difference in scores lying between 1.88 and 4.23 . This suggests that the interactive learning method does have a positive effect on the students' marks. The finding is in line with the study by Johnson et al. (2009), who found that the interactivity of educational system software is significantly related to course performance. It is also consistent with Chance et al. (2007), who claim that the introduction of technology in interactive teaching and learning would increase learning satisfaction and, in turn, learning ability among the students. The findings of the present study are also in line with the finding of Wang et al. (2015), who found that the active engagement of students in the learning process had a significant impact on student performance.

\subsection{Discussion}

The use of interactive learning using e-SampTec II, especially for statistical subjects, provides evidence on student performance enhancement. This entails that the e-learning system conveys learning assistance to the students in their courses, and the students were thus satisfied and, in turn, achieved better course performance (Islam et al., 2015). The findings of this study also indicate that the students felt that the learning was easy and flexible since they could learn using e-SampTec II for as much time as they required. The effectiveness of the system provides an opportunity for students to enhance their overall understanding, choose the right sampling techniques, and improve their performance in the statistics subject. The findings are also consistent with Pena-Sanchez (2009), who reveals that the results of the students that used interactive statistical software were better than those who do not use interactive statistical software. Since previous studies highlight that students often consider the statistical subject as difficult to understand, the findings of this study provide a significant contribution to help improve students' interest and to gain a deeper understanding of statistics. The findings of the study also support the empirical evidence on the generational changes among students and highlight the importance of using the e-SampTec II as an interactive learning tool, which is more relevant than traditional learning methods (Tawil et al., 2017). The emerging technologies suit the needs of today's students (the millennial generation) who are unique, as they have grown up in a digital world. These students are very confident in choosing the most preferred learning techniques that work best for them, such as interactive learning application tools (Barnes et al., 2007). Besides that, Novak et al. (2014) also found that using simulation-based learning for graduate students in an Introductory Statistics course provides a positive effect on the student's statistical knowledge and skill acquisition.

Nevertheless, the findings of this study are inconsistent with the results by Weltman and Whiteside (2010), who claim that the effectiveness of teaching and learning is not exclusively dependent on the method used, but instead on the students' characteristics such as cumulative grade point average level, which is equally essential. Some good students are still comfortable traditional teaching methods, while lower-ability students prefer interactive learning (Jamie, 2002). Overall, interactive learning increases students' involvement and interest in the subject being taught by engaging them in activities (Krusche et al., 2017). Thus, it attracts their attention and enhances confidence in learning technical issues. Due to the interactive nature of the tool and the excitement that today's students have with technology, e-SampTec II manages to meet this concept and, in turn, enhances their performance.

\subsection{Conclusion \& Recommendations}

In conclusion, the traditional teaching and learning method for the Introduction of Statistics course, which uses markers and whiteboards, may hinder the potential of better learning progress for students at higher learning education. Interactive teaching and learning have been at the forefront of a continuous effort to promote a wider implementation of e-learning practices in the university system (Endut et al., 2012). The motivation of researchers to embark on technology-based pedagogy in teaching the most challenging topic in statistics (i.e., sampling techniques) is based on their desire to overcome the scenario of constant low marks obtained by students. Therefore, based on the positive view of the students' experience using the interactive learning method in this study, there is a need for strong efforts to integrate technology into the design of interactive courseware, which should be implemented in the sampling techniques topic. This effort seems more promising in teaching students who are technologically literate. Specifically, this study provides evidence on the usefulness of e-SampTec II as an interactive application tool in teaching and learning to the technologically literate generation. Consequently, it can also be used by and aid researchers globally in conducting their research. Therefore, the usefulness that is derived from using the interactive tool is not limited to learners and educators but is also extended to researchers on a global scale. Further studies can be carried out in the future on the usefulness and effectiveness of interactive application tools (e-SampTec II) from the perspective of the researchers.

\section{Acknowledgments}

This work is financially supported by the Research Management and Innovation Institute (IRMI) under Research Grant iRAGS, Universiti Teknologi MARA, Project Number 600-RMI/IRAGS 5/3 (55/2015). Special thanks to the Administrative staff of Universiti Teknologi MARA for their support.

\section{References}

Al-Hariri, M. T. \& Al-Hattami, A. A. (2017). Impact of students' use of technology on their learning achievements in physiology courses at the University of Dammam. 
Journal of Taibah University Medical Sciences, 12(1), 82-85.

Aliasgari, M., Riahinia, N. \& Mojdehavar, F. (2010). Computer-assisted instruction and student attitudes towards learning mathematics. Education, Business and Society: Contemporary Middle Eastern Issues, 3(1), 6-14.

Chance, B., Ben-Zvi, D., Garfield, J. \& Medina, E. (2007). The Role of Technology in Improving Student Learning of Statistics. Technology Innovations in Statistics Education, 1(1), 1-26.

Chang, V. (2016). Review and discussion: E-learning for academia and industry. International Journal of Information Management, 36(3), 476-485.

Endut, A., Isa, P. M., Aziz, S. R. A., Jono, M. N. H. H. \& Aziz, A. A. (2012). e-Learning for Universiti Teknologi MARA Malaysia (UiTM): Campus Wide Implementation and Accomplishments. Procedia - Social and Behavioral Sciences, 67(November 2011), 26-35.

Gunasekaran, A., McNeil, R. D. \& Shaul, D. (2002). E-learning: research and applications. Industrial and Commercial Training, 34(2), 44-53.

Halachev, P. (2009a). Educational challenges for e-learning in higher education in Bulgaria. International Journal of Learning, 16(6), 737-746.

Halachev, P. (2009b). E-learning effectiveness. Icl-Conference.Org, pp. Vol. 1, 551-557.

Islam, N., Beer, M., \& Slack, F. (2015). E-Learning Challenges Faced by Academics in Higher Education: A Literature Review. Journal of Education and Training Studies, 3(5). https://doi.org/10.11114/jets.v3i5.947

Ivanović, M., Milićević, A. K., Aleksić, V., Bratić, B. \& Mandić, M. (2018). Experiences and perspectives of Technology-enhanced learning and teaching in higher education - Serbian case. Procedia Computer Science, 126, 1351-1359.

Jamie, D. M. (2002). Using Computer Simulation Methods to Teach Statistics: A Review of the Literature. Journal of Statistics Education, 10(1).

JavierSese1, L.-A.-O. (2013). Using clickers in class. The role of interactivity, active collaborative learning, and engagement in learning performance. Computers \& Education, 62, 102-110.

Johnson, R. D., Gueutal, H. \& Falbe, C. M. (2009). Technology, trainees, metacognitive activity, and e-learning effectiveness. Journal of Managerial Psychology, 24(6), 545-566.

Liaw, S. S. (2008). Investigating students' perceived satisfaction, behavioral intention, and effectiveness of e-learning: A case study of the Blackboard system. Computers and Education, 51(2), 864-873.

Macgregor, G. \& Turner, J. (2009a). Revisiting e-learning effectiveness: proposing a conceptual model. Interactive Technology and Smart Education, 6(3), 156-172.

Macgregor, G. \& Turner, J. (2009b). Revisiting e-learning effectiveness: proposing a conceptual model. Interactive Technology and Smart Education, 6(3), 156-172.

Mrinal Patwardh \& Sahana Murthy. 2015. When does a higher degree of interaction lead to higher learning in visualizations? Exploring the role of 'Interactivity Enriching Features.' Computers \& Education, 82, 292-305.

Novak, E., Johnson, T. E., Tenenbaum, G. \& Shute, V. J. (2014). Effects of an instructional gaming characteristic on learning effectiveness, efficiency, and engagement: using a storyline for teaching necessary statistical skills. Interactive Learning Environments, 24(3), 523-538.

Pena-sanchez, R. (2009). Interactive software usage for e-learning of business statistics. Competitiveness Review: An International Business Journal, 19(5), 391-397.

Qudrat-Ullah, H. (2010). Perceptions of the effectiveness of system dynamics-based interactive learning environments: An empirical study. Computers \& Education, 55(3), $1277-1286$.

Sawang, S., Newton, C. \& Jamieson, K. (2013). Increasing learners' satisfaction/intention to adopt more e-learning. Education + Training, 55(1), 83-105.

Tawil, N. M., Ismail, N. A., Asshaari, I., Osman, H. \& Nopiah, Z. M. (2017). Learning Process in Mathematics and Statistics Courses towards Engineering Students : Elearning or Traditional Method? 8(16), 128-133.

Wang, X., Yang, D., Wen, M., Koedinger, K. \& Rosé, C. P. (2015). Investigating how student's cognitive behavior in MOOC discussion forums affect learning gains International Educational Data Mining Society., 226-233.

Weltman, D. \& Whiteside, M. (2010). Comparing the Effectiveness of Traditional and Active Learning Methods in Business Statistics: Convergence to the Mean. Journal of Statistics Education, 18(1), 13.

Zhang, D., Zhao, J. L., Zhou, L. \& Nunamaker, J. F. (2004). Can e-Learning Replace Classroom Learning? Communications of the ACM, 47(5), 74-79.

Zhang, D., Zhou, L., Briggs, R. O. \& Nunamaker, J. F. (2006). Instructional video in e-learning: Assessing the impact of interactive video on learning effectiveness Information and Management, 43(1), 15-27. 